\title{
Comparison of updates to the Molly cow model to predict methane production from dairy cows fed pasture
}

\author{
P. Gregorini, ${ }^{* 1}$ P. C. Beukes, ${ }^{\star}$ M. D. Hanigan, $\dagger$ G. Waghorn, ${ }^{*}$ S. Muetzel, $\ddagger$ and J. P. McNamara§ \\ *DairyNZ Ltd., Private Bag 3221, Hamilton, New Zealand \\ †Virginia Polytechnic Institute and State University, Blacksburg 24061 \\ $\ddagger$ AgResearch, Grasslands, Private Bag 11008, Palmerston North, New Zealand \\ §Washington State University, Department of Animal Sciences, Pullman 99163
}

\begin{abstract}
Molly is a deterministic, mechanistic, dynamic model representing the digestion, metabolism, and production of a dairy cow. This study compared the predictions of enteric methane production from the original version of Molly (MollyOrigin) and 2 new versions of Molly. Updated versions included new ruminal fiber digestive parameters and animal hormonal parameters (Molly84) and a revised version of digestive and ruminal parameters (Molly85), using 3 different ruminal volatile fatty acid (VFA) stoichiometry constructs to describe the VFA pattern and methane $\left(\mathrm{CH}_{4}\right)$ production (g of $\mathrm{CH}_{4} / \mathrm{d}$ ). The VFA stoichiometry constructs were the original forage and mixed-diet VFA constructs and a new VFA stoichiometry based on a more recent and larger set of data that includes lactate and valerate production, amylolytic and cellulolytic bacteria, as well as protozoal pools. The models' outputs were challenged using data from 16 dairy cattle 26 mo old [standard error of the mean $(\mathrm{SEM})=1.7$ ], $82(\mathrm{SEM}$ $=8.7) \mathrm{d}$ in milk, producing $17(\mathrm{SEM}=0.2) \mathrm{kg}$ of milk/d, and fed fresh-cut ryegrass [dry matter intake $=$ $12.3(\mathrm{SEM}=0.3) \mathrm{kg}$ of $\mathrm{DM} / \mathrm{d}]$ in respiration chambers. Mean observed $\mathrm{CH}_{4}$ production was $266 \pm 5.6 \mathrm{SEM}$ (g/d). Mean predicted values for $\mathrm{CH}_{4}$ production were 287 and $258 \mathrm{~g} / \mathrm{d}$ for MollyOrigin without and with the new VFA construct. Model Molly84 predicted 295 and $288 \mathrm{~g}$ of $\mathrm{CH}_{4} / \mathrm{d}$ with and without the new VFA settings. Model Molly85 predicted the same $\mathrm{CH}_{4}$ production $(276 \mathrm{~g} / \mathrm{d})$ with or without the new VFA construct. The incorporation of the new VFA construct did not consistently reduce the low prediction error across the versions of Molly evaluated in the present study. The improvements in the Molly versions from MollyOrigin to Molly84 to Molly85 resulted in a decrease in mean square prediction error from 8.6 to 8.3 to $4.3 \%$ using the forage diet setting. The majority of the mean
\end{abstract}

Received October 18, 2012.

Accepted April 23, 2013.

${ }^{1}$ Corresponding author: Pablo.Gregorini@dairynz.co.nz square prediction error was apportioned to random bias (e.g., 43, 65, and 70\% in MollyOrigin, Molly84, and Molly85, respectively, on the forage setting, showing that with the updated versions a greater proportion of error was random). The slope bias was less than $2 \%$ in all cases. We concluded that, of the versions of Molly used for pastoral systems, Molly 85 has the capability to predict $\mathrm{CH}_{4}$ production from grass-fed dairy cows with the highest accuracy.

Key words: rumen metabolic model, methane production, pasture diet

\section{INTRODUCTION}

Molly is a deterministic, mechanistic, dynamic model representing the digestion, metabolism, and production of a dairy cow (Baldwin, 1995). The model is constructed at an aggregated biochemical pathway level to describe ruminal degradation and fermentation of feedstuffs, microbial growth, digestion, and absorption of nutrients and metabolism in the viscera, body, and mammary gland. Ruminal fermentation patterns determine the relative amount of different VFA and hydrogen production, and thus methanogenesis in the rumen. Benchaar et al. (1998) reported that the original VFA stoichiometry data set (Murphy et al., 1982), which is used in the original version of Molly (Baldwin, 1995), predicted enteric methane $\left(\mathrm{CH}_{4}\right)$ more accurately than empirical models. However, the prediction error from this VFA data set was high (37\%; Benchaar et al., 1998). High mean square prediction errors (MSPE) were also reported for the Murphy et al. (1982) construct by Kebreab et al. (2008) and later by Ellis et al. (2012) for Molly's $\mathrm{CH}_{4}$ module. However, these studies only compared ruminal VFA stoichiometries; they did not actually evaluate the results from the entire model, which includes other ruminal processes such as fiber degradation rates and rates of VFA absorption.

Since Baldwin (1995), Molly has been improved to simulate lipid metabolism (McNamara and Baldwin, 2000), lactation curves (Palliser and Woodward, 2002), photoperiod effect (Beukes et al., 2005), lactation 
potential (Hanigan et al., 2008), and anabolic and catabolic hormone dynamics, as well as gestational metabolism (Hanigan et al., 2009). Digestion parameters in the updated version of Molly (Hanigan et al., 2009) were derived using data from the literature, improving the original data derived by Baldwin et al. (1987a,b,c). However, prediction errors for VFA concentrations were still biased. Subsequently, Hanigan et al. (2013) rederived ruminal (e.g., intercept for $\mathrm{pH}$ prediction, slope for VFA effect on $\mathrm{pH}$, and rate constant for acetate, propionate, and butyrate absorption) and postruminal (e.g., intestinal digestion coefficient for starch, fiber, lipid, and protein) among other digestive parameters of Molly (Hanigan et al., 2009), reducing the slope bias for predictions of VFA proportions and postruminal digestion of fiber. Previously Nagorcka et al. (2000) extended the rumen processes in Molly (Baldwin, 1995) to include 3 bacterial pools based on an updated data set on VFA production coming from pasture-based diets (Nagorcka et al., 2000). A full evaluation analysis of the Nagorcka et al. (2000) improvements to Molly (Baldwin, 1995) has not yet been conducted.

Despite these cumulative improvements, the version of Molly used for pastoral systems (Hanigan et al., 2013) has not been evaluated against observed data for $\mathrm{CH}_{4}$ production. One focus is to continue to challenge and improve behavior of the model on herbage-fed animals and pastoral systems. Therefore, the following question arises: how have the various versions of the Molly model affected the ability to predict $\mathrm{CH}_{4}$ production? The objective of this work was, therefore, to compare the performance of 3 different versions of Molly [Baldwin (1995), Hanigan et al. (2009), and Hanigan et al. (2013)]; with or without an updated alternative set of coefficients for VFA production in the rumen (Nagorcka et al., 2000) for the description of $\mathrm{CH}_{4}$ production in dairy cows fed a grass diet.

\section{MATERIALS AND METHODS}

\section{Models}

The Molly model was originally published in full in 1987 (Baldwin et al., 1987a,b,c) and has had several updates that have been published since then (Baldwin, 1995; Hanigan et al., 2009, 2013). The model accepts feed chemistry (starch, cellulose, hemicellulose, lignin, soluble protein, insoluble protein, fat, added fat, organic acids, soluble, and insoluble ash) and total DMI as explicit inputs and also contains several feeding strategies for intake, such as direct observations, feeding based on maintenance and milk production, feeding based on NDF content, or feeding based on NRC equations. In the rumen submodel, food enters as large particles, small particles, and soluble pools (proportions can be set as an input or as a function of the feed). Fiber and protein degradation rate constants can be changed to match different diets or research results. Insoluble protein is degraded to soluble protein, which is converted to amino acids to be used for microbial protein or degraded. Soluble components are fermented (starch, soluble carbohydrates, cellulose, hemicellulose, and excess amino acids) to acetate, propionate, butyrate, and lactate. Hydrogen from fermentation is converted to $\mathrm{CH}_{4}$ stoichiometrically (4 mol of hydrogen and 1 mol of carbon dioxide make $1 \mathrm{~mol}$ of $\mathrm{CH}_{4}$ ). Undigested particles pass from the rumen and are digested in the small or large intestine.

The animal model contains pools describing body (muscle and skin), viscera (liver, intestines, and pancreas), mammary glands, and adipose tissue. Metabolism is aggregated at the pathway level for body and visceral protein synthesis and degradation, lipogenesis, esterification, and lipolysis (adipose), and milk lactose, protein, and fat synthesis. The model accounts for all catabolic and anabolic reactions and resultant ATP synthesis or use and energy use is balanced at the ATP level (energy deficit is supplied by oxidation of glucose or FA; excess is stored as fat). Equation forms and parameter values were estimated from reported literature. Importantly, all the parameter values can be changed for each new simulation to compare with various experiments or conduct hypothesis testing (for example, what if fiber degradation rates were higher than average on a given diet?). The model has been evaluated in several different production and dietary systems [see references in Baldwin (1995), Hanigan et al. (2009), and McNamara (2012)].

The original rumen submodel was constructed to ferment soluble carbohydrate, starch, hemicellulose, and cellulose to acetate, propionate, and butyrate (and lactate, but only at $\mathrm{pH}<5.5$ ), using a meta-analytic data set (Murphy et al., 1982). In the original model, based on the major dietary component (forage and concentrate), 3 different VFA stoichiometric pattern constructs were developed from studies available at that time. The data to parameterize FORSET were the VFA patterns from high-forage diets (approximately 60 to $70 \%$ forage); for MIXSET, rations ranged from a forage:concentrate ratio of $40 \%$ forage: $60 \%$ concentrate to $60 \%$ forage: $40 \%$ concentrate, whereas rations containing $>60 \%$ concentrate, primarily from beef cattle finishing rations, were used for high-concentrate rations (CONSET). These settings should be based upon the type of diet being simulated, with most dairy diets being of the mixed variety. However, FORSET should be used for pasture-fed animals. Thus, in this experiment we used the FORSET setting to test the different ver- 
Table 1. Volatile FA production from the fermentation of soluble carbohydrate (Sc), starch (St), cellulose $(\mathrm{Ce})$, and hemicellulose $(\mathrm{Hc})$ in 2 approaches from 2 different meta-data sets and included in the Molly rumen submodel

\begin{tabular}{|c|c|c|c|c|c|}
\hline \multirow[b]{3}{*}{ Item $^{2}$} & & & \multicolumn{3}{|c|}{ Nagorcka et al. $(2000)^{4}$} \\
\hline & \multicolumn{2}{|c|}{ Murphy et al. $(1982)^{3}$} & \multicolumn{3}{|c|}{ BACTSET } \\
\hline & FORSET & MIXSET & AMYL & CELL & PROT \\
\hline $\mathrm{ScAc}$ & 1.38 & 1.14 & 0.713 & 0.00 & 0.74 \\
\hline $\mathrm{ScPr}$ & 0.40 & 0.43 & 0.396 & 0.00 & 0.00 \\
\hline $\mathrm{ScBu}$ & 0.11 & 0.21 & 0.198 & 0.00 & 0.49 \\
\hline ScLa & & 0.46 & 0.00 & & \\
\hline ScVal & & & 0.018 & 0.00 & 0.00 \\
\hline $\mathrm{ScCO}_{2}$ & & & 1.13 & 0.00 & 0.00 \\
\hline StAc & 1.20 & 1.00 & 0.71 & 0.00 & 0.98 \\
\hline $\mathrm{StPr}$ & 0.34 & 0.52 & 0.39 & 0.00 & 0.00 \\
\hline $\mathrm{StBu}$ & 0.23 & 0.24 & 0.19 & 0.00 & 0.49 \\
\hline StLa & & 0.46 & 0.00 & & \\
\hline StVal & & & 0.02 & 0.00 & 0.00 \\
\hline $\mathrm{StCO}_{2}$ & & & 1.12 & 0.00 & 0.00 \\
\hline $\mathrm{HcAc}$ & 1.14 & 1.13 & 0.00 & 1.00 & 1.00 \\
\hline $\mathrm{HcPr}$ & 0.40 & 0.49 & 0.35 & 0.36 & 0.00 \\
\hline $\mathrm{HcBu}$ & 0.23 & 0.19 & 0.23 & 0.25 & 0.5 \\
\hline $\mathrm{CeAc}$ & 1.32 & 1.45 & 0.00 & 1.27 & 0.98 \\
\hline $\mathrm{CePr}$ & 0.20 & 0.20 & 0.00 & 0.47 & 0.00 \\
\hline $\mathrm{CeBu}$ & 0.24 & 0.17 & 0.00 & 0.09 & 0.49 \\
\hline
\end{tabular}

${ }^{1}$ Numbers are moles of product produced per mole of substrate (St, Sc, Hc, and Ce) fermented.

${ }^{2} \mathrm{Ac}=$ acetate $\mathrm{Pr}=$ propionate $\mathrm{Bu}=$ butyrate $; \mathrm{La}=$ lactate $;$ Val $=$ valerate.

${ }^{3}$ FORSET $=$ VFA pattern from high-forage diets; MIXSET $=$ VFA pattern on mixed forage/concentrate rations.

${ }^{4}$ In the Nagorcka et al. (2000) construct, amylolytic bacteria ferment only soluble carbohydrate (CHO) and starch, cellulolytic bacteria ferment only cellulose and hemicellulose in the proportions shown, and protozoa ferment all substrates in the proportions shown. BACTSET = the Nagorcka et al. (2000) construct (bacterial pools VFA stoichiometry); AMYL = amylolytic bacteria; CELL = cellulolytic bacteria; PROT = protozoa.

sions of the model, as well as the MIXSET setting as an alternative setting to show the differences between the settings (Murphy et al., 1982). The VFA production rates for CONSET are shown in Table 1 for comparison; they were not used in this study.

This work reports on 3 versions of the model: the original model as described in Baldwin (1995; MollyOrigin), an updated version that included new digestive parameter values for fiber degradation (Hanigan et al. 2009; Molly84), and another update that included newer fiber degradation parameters and VFA uptake parameters based on a newer compilation of observed data from several studies (Hanigan et al., 2013; Molly85). In addition, in each of these versions, a new construct for VFA production from carbohydrate substrates was developed from a data set compiled from several studies published after the original Murphy et al. (1982) and before Nagorcka et al. (2000; Tables 1 and 2).

In the models including the new VFA stoichiometry, the original equation forms remained the same; however, the VFA stoichiometry was developed including a new construct of 3 pools: amylolytic bacteria, cellulolytic bacteria, and protozoa, each with a specific VFA pattern for each substrate (Table 1,2). As with MollyOrigin, in Molly84 and Molly85, VFA is still a function of substrate, but substrate use is subdivided between bacterial and protozoa pools. Each microbial pool ferments different substrates; for example, amylolytics only ferment starch and soluble carbohydrate, cellulytics only ferment cellulose and hemicellulose, and protozoa can ferment all 4 substrate classes, and thereby VFA production patterns are slightly different for each substrate/bacteria combination (Table 1). The production of lactate and valerate were also included in this construct. In MollyOrigin, Molly84, and Molly85, valerate is assigned to 0.5 butyrate and 1.0 propionate to maintain carbon balance. It should be noted that in most cases valerate is a relatively small proportion of total VFA. Herein, the Nagorcka et al. (2000) construct is referred to as BACTSET and for this initial study, a constant mix of 0.25 amylolytic, 0.25 cellulolytic, and 0.5 protozoa pools were used. In the full Nagorcka model, these bacterial pool proportions can be set explicitly or allowed to be functions of the feed; for this work, just a simple reference state was used (Nagorcka et al. 2000).

\section{Simulation Exercise}

To compare $\mathrm{CH}_{4}$ production (g/d) outcomes from the versions of the model, a $3 \times 3$ simulation exercise was 
Table 2. Equations to calculate proportions of VFA [acetate (Ac), propionate (Pr), valerate (Val), and lactate (La)] from amylolytic (Amyl) and cellulolytic (Cell) bacteria and protozoa (Prot) fermentation of soluble carbohydrates (Sc), starch (St), hemicellulose (Hc), and Cellulose (Ce) in the Nagorcka et al. (2000) VFA model

\begin{tabular}{ll}
\hline From $\mid$ to & Equation \\
\hline $\mathrm{Sc} \mid \mathrm{Pr}$ & $=($ AmylScPr $\times$ Amyl $\times 2+$ ProtScPr $\times$ Prot $)$ \\
$\mathrm{Sc} \mid \mathrm{Bu}$ & $=($ AmylScBu $\times$ Amyl $\times 2+$ ProtScBu $\times$ Prot $)$ \\
$\mathrm{Sc} \mid \mathrm{Val}$ & $=($ AmylScVal $\times$ Amyl $\times 2+$ ProtScVal $\times$ Prot $)$ \\
$\mathrm{Sc} \mid \mathrm{La}$ & $=($ AmylScLa $\times$ Amyl $\times 2+$ ProtScLa $\times$ Prot $)$ \\
$\mathrm{Sc} \mid \mathrm{CO}_{2}$ & $=($ AmylScCO $\times$ Amyl $\times 2+$ ProtScCO \\
Prot & \\
$\mathrm{St} \mid \mathrm{Ac}$ & $=($ AmylStAc $\times$ Amyl $\times 2+$ ProtStAc $\times$ Prot $)$ \\
$\mathrm{St} \mid \mathrm{Pr}$ & $=($ AmylStPr $\times$ Amyl $\times 2+$ ProtStPr $\times$ Prot $)$ \\
$\mathrm{St} \mid \mathrm{Bu}$ & $=($ AmylStBu $\times$ Amyl $\times 2+$ ProtStBu $\times$ Prot $)$ \\
$\mathrm{St} \mid \mathrm{Val}$ & $=($ AmylStVal $\times$ Amyl $\times 2+$ ProtStVal $\times$ Prot $)$ \\
$\mathrm{St} \mid \mathrm{La}$ & $=($ AmylStLa $\times$ Amyl $\times 2+$ ProtStLa $\times$ Prot $)$ \\
$\mathrm{Hc} \mid \mathrm{Ac}$ & $=($ AmylHcAc $\times$ Amyl + CellHcAc $\times$ Cell + ProtHcAc $\times$ Prot $)$ \\
$\mathrm{Hc} \mid \mathrm{Pr}$ & $=($ AmylHcPr $\times$ Amyl + CellHcPr $\times$ Cell + ProtHcPr $\times$ Prot $)$ \\
$\mathrm{Hc} \mid \mathrm{Bu}$ & $=($ AmylHcBu $\times$ Amyl + CellHcBu $\times$ Cell + ProtHcBu $\times$ Prot $)$ \\
$\mathrm{Ce} \mid \mathrm{Ac}$ & $=($ CellCeAc $\times$ Cell $\times 2+$ ProtCeAc $\times$ Prot $)$ \\
$\mathrm{Ce} \mid \mathrm{Pr}$ & $=($ CellCePr $\times$ Cell $\times 2+$ ProtCePr $\times$ Prot $)$ \\
$\mathrm{Ce} \mid \mathrm{Bu}$ & $=($ CellCeBu $\times$ Cell $\times 2+$ ProtCeBu $\times$ Prot $)$ \\
\hline
\end{tabular}

conducted using a factorial combination of MollyOrigin, Molly84, and Molly85 with FORSET, MIXSET, CONSET, and BACTSET constructs. The model code was developed and simulations were conducted using acslXtreme software (version 2.5.0.6; AEgis Technologies Group Inc., Austin, TX). Numerical integration was conducted using a fourth-order, fixed-step, RungeKutta method. The maximum integration interval was set to $1 \mathrm{~d}$. Results were collected after $28 \mathrm{~d}$ of simulation to ensure that the model had reached a stable state.

The model outputs were challenged using data from 16 dairy cattle, which were fed fresh cut Lolium perenne L. in respiration chambers at AgResearch Grasslands (Palmerston North, New Zealand). The cattle averaged $26 \mathrm{mo}$ old $(\mathrm{SEM}=1.7)$, were $82(\mathrm{SEM}=8.7) \mathrm{DIM}$, consumed $12.3(\mathrm{SEM}=0.3) \mathrm{kg}$ of $\mathrm{DM} / \mathrm{d}$, and produced $17(\mathrm{SEM}=0.2) \mathrm{kg}$ of milk/d. Before the measurement period, cattle were adapted to confinement conditions by placing them for $10 \mathrm{~d}$ in metabolic cages. After this adaptation period, cattle were placed in the respiration chamber for a period of $2 \mathrm{~d}$ when measurements took place. Chemical composition of herbage offered (10 samples) and refused (10 samples) was determined every day during the adaptation and measurements periods, using a near-infrared spectrophotometer (Bruker MPA, multipurpose analyzer; Bruker Optik GmbH, Ettlingen, Germany). The DMI was recorded for each cow. Methane production ranged from 228 to $350 \mathrm{~g} / \mathrm{d}$. This relatively wide range of production on the same diet provided a good model challenge (Table 3 ).

Individual cow data (average of 2 measurements days) were used as the observed data set. Inputs into the models were the observed DMI, feed chemical composition, and the starting BW of the animals (Table 3 ). Milk production and composition were set in the model using the genetic scalars and maximal velocities for fat and protein synthesis to match each animal's actual production.

Mean predicted and observed values were compared by an F-test for each version and VFA setting combination of the model. Residual errors of prediction were used to calculate root mean square prediction errors. The MSPE was partitioned into mean, slope, and random bias and expressed as a percentage of the observed means.

\section{RESULTS AND DISCUSSION}

The production of $\mathrm{CH}_{4}$ is a direct function of the generation of carbon dioxide and hydrogen in the rumen (Hungate, 1966). In the model, some products of ruminal fermentation result in the formation of $\mathrm{CH}_{4}$ as a sink for excess hydrogen (Baldwin, 1995). This module of $\mathrm{CH}_{4}$ formation was used by Benchaar et al. (1998) and Mills et al. (2001). Therefore, differences in $\mathrm{CH}_{4}$ production are a direct result of changes in ruminal fermentation pattern and, thereby, VFA stoichiometric settings. The results of the simulation exercise are presented in Table 4.

In MollyOrigin, the FORSET construct predicted 8.6\% more, whereas the MIXSET setting predicted $11.5 \%$ less $\mathrm{CH}_{4}$ than observed. This was expected because the MIXSET setting represents a mixed diet, whereas the cows were fed $100 \%$ forage. The BACTSET setting in MollyOrigin provided a $\mathrm{CH}_{4}$ estimate only $2.4 \%$ lower than observed, showing the improvement to the original model to predict the $\mathrm{CH}_{4}$ for this type of diet when a newer and more appropriate data set is used (Nagorcka et al., 2000). The F-statistic values for comparing predicted $\mathrm{CH}_{4}$ production with observed 
Table 3. Dry matter intake, dietary chemical composition, and $\mathrm{CH}_{4}$ production, of dairy cows $(\mathrm{n}=16)$ fed fresh cut Lolium perenne $\mathrm{L}$. in respiration chambers

\begin{tabular}{|c|c|c|c|c|c|c|c|c|c|c|c|c|c|c|c|c|}
\hline \multirow[b]{2}{*}{ Item } & \multirow[b]{2}{*}{ DIM } & \multirow{2}{*}{$\begin{array}{l}\mathrm{BW} \\
(\mathrm{kg})\end{array}$} & \multirow[b]{2}{*}{$\mathrm{BCS}^{1}$} & \multirow{2}{*}{$\begin{array}{c}\text { DMI } \\
(\mathrm{kg} / \mathrm{d})\end{array}$} & \multirow{2}{*}{$\begin{array}{c}\mathrm{CH}_{4} \\
(\mathrm{~g} / \mathrm{d})\end{array}$} & \multicolumn{11}{|c|}{ Dietary composition $^{2}$ (decimal percentage of DM) } \\
\hline & & & & & & $\mathrm{Sc}$ & $\mathrm{Ce}$ & $\mathrm{Hc}$ & $\operatorname{Lg}$ & St & Ps & $\mathrm{Pi}$ & $\mathrm{Li}$ & $\mathrm{Pe}$ & $\mathrm{Ai}$ & As \\
\hline Mean & 82 & 415.7 & 4.67 & 12.33 & 265.8 & 0.064 & 0.252 & 0.291 & 0.040 & 0.032 & 0.095 & 0.095 & 0.018 & 0.030 & 0.040 & 0.040 \\
\hline Minimum & 67 & 373.0 & 3.50 & 9.90 & 227.7 & 0.011 & 0.232 & 0.240 & 0.040 & 0.032 & 0.079 & 0.079 & 0.003 & 0.030 & 0.017 & 0.017 \\
\hline Maximum & 101 & 469.0 & 5.00 & 14.90 & 350.3 & 0.101 & 0.272 & 0.321 & 0.040 & 0.032 & 0.107 & 0.107 & 0.030 & 0.030 & 0.077 & 0.077 \\
\hline
\end{tabular}

${ }^{1} \mathrm{Scale}$ of 1 to 9.
${ }^{2} \mathrm{Sc}=$ soluble carbohydrate; $\mathrm{Ce}=$ cellulose; $\mathrm{Hc}=$ hemicellulose; $\mathrm{Lg}=$ lignin $; \mathrm{St}=$ starch, $\mathrm{Ps}=$ soluble protein; $\mathrm{Pi}=$ insoluble protein; Li = lipids; Pe = pectin; Ai = insoluble
ash; As = soluble ash.

Table 4. Descriptions of $\mathrm{CH}_{4}$ production by the original version of the Molly cow model and 2 updated versions (Molly84 and Molly85) with 3 VFA stoichiometry constructs (FORSET, MIXSET, and BACTSET), simulating a study of dairy cattle fed fresh Lolium perenne L. in respiration chambers ${ }^{1}$

\begin{tabular}{|c|c|c|c|c|c|c|c|c|c|c|}
\hline \multirow[b]{3}{*}{ Item } & \multirow{3}{*}{$\begin{array}{c}\text { Observed } \\
\mathrm{CH}_{4}(\mathrm{~g} / \mathrm{d})\end{array}$} & \multicolumn{9}{|c|}{ Predicted } \\
\hline & & \multicolumn{3}{|c|}{ Molly85 } & \multicolumn{3}{|c|}{ Molly84 } & \multicolumn{3}{|c|}{ MollyOrigin } \\
\hline & & FORSET & MIXSET & BACTSET & FORSET & MIXSET & BACTSET & FORSET & MIXSET & BACTSET \\
\hline Mean & 266 & 276 & 263 & 276 & 288 & 279 & 295 & 287 & 234 & 258 \\
\hline Minimum & 228 & 215 & 207 & 216 & 233 & 227 & 238 & 248 & 197 & 218 \\
\hline Maximum & 350 & 344 & 329 & 342 & 351 & 341 & 363 & 335 & 281 & 306 \\
\hline SD & 30.1 & 38.3 & 35.6 & 37.8 & 40.0 & 38.9 & 40.5 & 29.0 & 25.7 & 30.1 \\
\hline CV $(\%)$ & 11.3 & 13.9 & 13.5 & 13.7 & 13.9 & 13.9 & 13.7 & 10.1 & 11.0 & 11.7 \\
\hline Predicted - observed $(\mathrm{g} / \mathrm{d})$ & & 10 & -2 & 10 & 21 & 12 & 29 & 21 & -32 & -8.2 \\
\hline SEM of difference $(\mathrm{g} / \mathrm{d})$ & & 6.4 & 5.9 & 6.4 & 6.5 & 6.4 & 7.1 & 5.8 & 4.7 & 5.7 \\
\hline Predicted - observed (\%) & & 4.30 & -0.38 & 4.30 & 8.3 & 5.0 & 11.7 & 8.6 & -11.5 & -2.4 \\
\hline SEM of difference ( $\%$ ) & & 2.4 & 2.2 & 2.4 & 2.7 & 2.4 & 2.4 & 2.2 & 2 & 2.1 \\
\hline $\operatorname{MSPE}^{2}(\mathrm{~g} / \mathrm{d})$ & & 36 & 32 & 36 & 36 & 48 & 40 & 37 & 45 & 32 \\
\hline Mean bias ( $\%$ of MSPE) & & 28 & -7 & 27 & 34 & 61 & 50 & 55 & 72 & 26 \\
\hline Slope bias (\% of MSPE) & & 1.7 & 1.7 & 1.7 & 1.6 & 1 & 1.5 & 1.6 & 1 & 1 \\
\hline Random bias ( $\%$ of MSPE) & & 70 & 91 & 71 & 65 & 38 & 49 & 43 & 27 & 73 \\
\hline
\end{tabular}

${ }^{1}$ MollyOrigin = original version published by Baldwin (1995); Molly84 = version based on Hanigan et al. (2009); Molly85 = version based on Hanigan et al. (2013); FORSET and MIXSET (Murphy et al., 1982) = forage and mixed-diet VFA stoichiometry, respectively; BACTSET (Nagorcka et al., 2000) = bacterial pools VFA stoichiometry. The F-statistic values for comparing predicted $\mathrm{CH}_{4}$ production with observed were $0.59,0.82$, and 0.36 for BACTSET, FORSET, and MIXSET.

${ }^{2}$ Mean square prediction error. 
were $0.59,0.82$, and 0.36 for BACTSET, FORSET, and MIXSET, indicating no difference between predicted and observed. The coefficient of variation of observations between cows was $11.3 \%$. Except for the MIXSET setting in MollyOrigin, the 3 constructs in fact were within the animal-to-animal variation. It should to be noted that the MIXSET construct was not meant to be used on high-forage diets as fed here, so it is not surprising this was the least best fit.

In Molly84, all predictions were within 1 standard deviation of the mean (Table 4), but subtle differences were observed between MIXSET ( $5 \%$ higher than observed), FORSET (8.3\% higher), and BACTSET (11.7\% higher than observed). The overall coefficient of variation of the predicted mean was approximately $13.8 \%$. The F-statistic values for predicted versus observed were $0.12,0.18$, and 0.24 , for BACTSET, FORSET, and MIXSET, indicating no difference between predicted and observed. The major relevant update in Molly84 was a change in fiber degradation parameters to fit newer data (Hanigan et al., 2009) compared with the original data set of Murphy et al. (1982). Thus, it is not surprising to find a slightly different fit. It is noted again here that in the MollyOrigin, Molly84, and Molly85 versions, although parameter values for fiber degradation were changed, the VFA production stoichiometry was always the original Murphy et al. (1982) construct.

In Molly85, FORSET and BACTSET were both $4.3 \%$ above observed $\mathrm{CH}_{4}$ production values, whereas MIXSET was similar to that observed $(0.4 \%$ lower than observed) and the coefficient of variation of the predicted mean remained about $13.9 \%$. The mean difference between predicted and observed was lower in all 3 settings of Molly85. This indicates that the updates to the fiber and protein degradation parameters, plus the update to the acetate absorption parameter, helped improve the fit of $\mathrm{CH}_{4}$ production, and reiterates that almost all the predictions were within the observed coefficient of variation range. The $\mathrm{F}$-statistic values were $0.24,0.21$, and 0.39 for BACTSET, FORSET, and MIXSET, respectively, for Molly85.

The residual analysis demonstrated that the model updates Molly84 and Molly85 increased the accuracy of prediction, shifting most of the error from mean bias to random bias. Briefly, the Molly84 model (Hanigan et al., 2009) included updated fiber degradation parameter values based on a data set from several studies used in the NRC revision (NRC, 2001), a much larger data set than the original Murphy data set (Murphy et al., 1982). The Molly85 version (Hanigan et al., 2013) refitted these parameters, as well as VFA absorption rate parameters from another data set compiled from studies conducted after the NRC update. Thus, it is reasonable that these newer parameter values would fit recent observations more closely than using data from studies more than $30 \mathrm{yr}$ old and with a large proportion of VFA data from sheep. This should not be taken as a criticism of the original model; rather, as a confirmation that the original model construct was robust enough to allow updates of parameter values that improved the fit to newer observations. That is, equation forms did not need to be changed; rather, simple adjustments to parameter settings improved performance.

Thus, MollyOrigin contained inadequate values for parameters such as fiber degradation rates and VFA absorption rates, which Molly84 and Molly85 directly address. Although mean bias in the FORSET and BACTSET constructs in Molly85 were 28 and $27 \%$ of total prediction error, the total prediction error was less than the coefficient of variation among animals, and the F-statistics between predicted and observed were all nonsignificant, indicating the model predicted reality as well as it can be measured at present. These improvements in the ability of Molly to fit a wider range of data in the specific situation here (fresh grassfed dairy cows) demonstrate the utility of the model to answer research questions and help predict $\mathrm{CH}_{4}$ production from pasture-based diets.

Changes in ruminal process parameters in the newer versions of Molly are relatively small compared with the wide range of diets and production situations. For $\mathrm{CH}_{4}$ production, the driving forces remain the amount and balance of fermentable substrates consumed, and the updates did not change the underlying chemical stoichiometry of VFA production, indicating room for improvements in the prediction of $\mathrm{CH}_{4}$ by the model.

\section{CONCLUSIONS}

The improvements in the original version of Molly to Molly84 to Molly85 resulted in a decrease in the proportion of mean relative prediction error and supported better predictions of $\mathrm{CH}_{4}$ production. The incorporation of the new VFA construct did not consistently reduce the MSPE of $\mathrm{CH}_{4}$ production across the versions of Molly evaluated in the present study. We concluded that the version of Molly used for pastoral systems, Molly85, provides a more accurate prediction of $\mathrm{CH}_{4}$ production from grass-fed dairy cows than previous Molly versions. Potential improvements should focus on the prediction of ruminal VFA production rather than concentration, as well as the intake patterns and the associated changes in nutrient release in the rumen and fermentation patterns.

\section{ACKNOWLEDGMENTS}

The work was funded by a SLMACC project (C1OXO902; Systems analysis to quantify the role 
of farm management in GHG emissions and sinks for pastoral sectors) and New Zealand dairy farmers by DairyNZ (Hamilton, New Zealand). Andrew Young and Eric Zurcher [Commonwealth Scientific and Industrial Research Organisation (CSIRO), Clayton South, Victoria, Australia] helped with the coding and modeling efforts of the Nagorcka et al. (2000) setting in the present work.

\section{REFERENCES}

Baldwin, R. L. 1995. Modeling Ruminant Digestion and Metabolism. Chapman and Hall, London, UK.

Baldwin, R. L., J. France, D. E. Beever, M. Gill, and J. H. Thornley. 1987a. Metabolism of the lactating cow. III. Properties of mechanistic models suitable for evaluation of energetic relationships and factors involved in the partition of nutrients. J. Dairy Res. $54: 133-145$.

Baldwin, R. L., J. France, and M. Gill. 1987b. Metabolism of the lactating cow. I. Animal elements of a mechanistic model. J. Dairy Res. 54:77-105.

Baldwin, R. L., J. H. Thornley, and D. E. Beever. 1987c. Metabolism of the lactating cow. II. Digestive elements of a mechanistic model. J. Dairy Res. 54:107-131.

Benchaar, C., J. Rivest, C. Pomar, and J. Chiquette. 1998. Prediction of methane production from dairy cows using existing mechanistic models and regression equations. J. Anim. Sci. 76:617-627.

Beukes, P. C., B. S. Thorrold, M. E. Wastney, C. C. Palliser, K. A. Macdonald, K. P. Bright, J. A. S. Lancaster, C. A. J. Palmer, and M. J. Auldist. 2005. Modelling the bi-peak lactation curves of summer calvers in New Zealand dairy farm systems. Aust. J. Exp. Agric. 45:643-650.

Ellis, J. L., J. Dijkstra, J. France, A. J. Parsons, G. R. Edwards, S. Rasmussen, E. Kebreab, and A. Bannink. 2012. Effect of highsugar grasses on methane emissions simulated using a dynamic model. J. Dairy Sci. 95:272-285.

Hanigan, M. D., J. A. D. R. N. Appuhamy, and P. Gregorini. 2013. Revised digestive parameter estimates for the Molly cow model. J. Dairy Sci. 96:3867-3885. http://dx.doi.org/10.3168/jds.2012-6183.
Hanigan, M. D., C. C. Palliser, and P. Gregorini. 2009. Altering the representation of hormones and adding consideration of gestational metabolism in a metabolic cow model reduced prediction errors. J. Dairy Sci. 92:5043-5056.

Hanigan, M. D., C. C. Palliser, and A. G. Rius. 2008. Modelling lactation potential in an animal model. Pages 485-507 in Mathematical Modelling in Animal Nutrition. J. France and E. Kebreab, ed. CAB International, Wallingford, UK.

Hungate, R. E. 1966. The Rumen and its Microbes. Academic Press, New York, NY.

Kebreab, E., K. A. Johnson, S. L. Archibeque, D. Pape, and T. Wirth. 2008. Model for estimating enteric methane emissions from United States dairy and feedlot cattle. J. Anim. Sci. 86:2738-2748.

McNamara, J. P., and R. L. Baldwin. 2000. Estimation of parameters describing lipid metabolism in lactation: Challenge of existing knowledge described in a model of metabolism. J. Dairy Sci. $83: 128-143$.

McNamara, J. P. 2012. Integrating nutritional, genetic and reproductive management in early lactation dairy cattle. J. Anim. Sci 90:1846-1854.

Mills, J. A. N., J. Dijkstra, A. Bannink, S. B. Cammell, E. Kebreab, and J. France. 2001. A mechanistic model of whole-tract digestion and methanogenesis in the lactating dairy cow: Model development, evaluation, and application. J. Anim. Sci. 79:1584-1597.

Murphy, M. R., R. L. Baldwin, and L. J. Koong. 1982. Estimation of stoichiometric parameters for rumen fermentation of roughage and concentrate diets. J. Anim. Sci. 55:411-421.

Nagorcka, B. N., G. L. R. Gordon, and R. A. Dynes. 2000. Towards a more accurate representation of fermentation in mathematical models of the rumen. Pages 37-47 in Modelling Nutrient Utilization in Farm Animals. J. P. McNamara, J. France, and D. E. Beever, ed. CAB International, Wallingford, UK.

NRC. 2001. Nutrient Requirements of Dairy Cattle. 7th rev. ed. National Academy Press, Washington, DC.

Palliser, C. C., and S. L. Woodward. 2002. Using models to predict methane reduction in pasture-fed dairy cows. Pages 162-167 in Int. Environ. Modelling Software Soc. (iEMSs) Conf., University of Lugano, Italy. 